\title{
Vulnerability of field crops to midcentury temperature changes and yield effects in the Southwestern USA
}

\author{
Emile Elias $^{1}$ (D) Alison Marklein ${ }^{2,3}$ • \\ John T. Abatzoglou ${ }^{4} \cdot$ Jake Dialesandro $^{5}$ - Joel Brown ${ }^{6}$. \\ Caiti Steele $^{7} \cdot$ Albert Rango $^{1} \cdot$ Kerri Steenwerth $^{8}$
}

Received: 29 June 2017 / Accepted: 24 October 2017 / Published online: 28 November 2017

(C) The Author(s) 2017. This article is an open access publication

\begin{abstract}
Increased temperatures in the Southwestern USA will impact future crop production via multiple pathways. We used four methods to provide an illustrative analysis of midcentury temperature impacts to eight field crops. By midcentury, cropland area thermally suitable for maize cultivation is projected to decrease, while area suitable for cotton cultivation expands
\end{abstract}

This article is part of a Special Issue on 'Vulnerability of Regional Forest and Agricultural Ecosystems to a Changing Climate (USDA Southwest Climate Hub)' edited by David Gutzler and Connie Maxwell.

Electronic supplementary material The online version of this article (https://doi.org/10.1007/s10584-0172108-8) contains supplementary material, which is available to authorized users.

Emile Elias

emile.elias@ars.usda.gov

Alison Marklein

alisonmarklein@1bl.gov

John T. Abatzoglou

jabatzoglou@uidaho.edu

Jake Dialesandro

jdiales@ucdavis.edu

Joel Brown

joelbrow@nmsu.edu

Caiti Steele

caiti@nmsu.edu

Albert Rango

al.rango@ars.usda.gov

Kerri Steenwerth

kerri.steenwerth@ars.usda.gov

1 Jornada Experimental Range, USDA-Agricultural Research Service, Las Cruces, Mexico 
northward and nearly doubles in extent. The increase in area exposed to daily temperatures $>35^{\circ} \mathrm{C}$ was highest for oat and maize. Estimates of yield reduction from heat stress for both maize and cotton indicate that historically, SW heat stress reduced cotton yield by $26 \%$ and maize yield by $18 \%$ compared to potential yield. By midcentury, we predict yield reduction from heat stress will reduce cotton and maize yields by 37 and $27 \%$, respectively, compared to potential yield. Our results contradict the notion that the warmest counties cultivating field crops will be the most impacted. Rather, future temperature, total crop area and crop sensitivity contribute to more complex county-level impacts. Identification of representative target environments under future temperature regimes can inform development of farm-based networks to evaluate new crop germplasm with increased heat tolerance and viable adaptation and management strategies to respond effectively to future temperatures.

\section{Introduction}

Assessing the magnitude and spatial extent of the impacts of climate change on crop yields is vital for meeting the needs of increasing populations and improving food security despite diminishing land available for agricultural expansion. By midcentury, the Southwestern USA (SW) is projected to experience higher temperatures and more frequent, intense and longer heat waves (Gershunov et al. 2013). Field crops (FC) in the SW are vulnerable to increased temperatures, which can accelerate crop growth, leading to earlier and often reduced yields, and also lead to heat stress or crop failure, particularly during certain phenological phases. The contraction of developmental stages in a warmer climate and consequent shift in regional crop suitability is a well-documented impact of climate change (Craufurd and Wheeler 2009; Walthall et al. 2012).

Warming impacts are crop-specific due to the unique temperature response thresholds at which optimal growth and crop failure occur (Robertson et al. 2013). Elevated temperatures may benefit crops currently below their optimal temperature threshold but reduce the growth of other crops near or past their thresholds (Lobell and Gourdji 2012; Marshall et al. 2015). Increased mean temperatures above the optimal threshold can shorten the growth cycle and grain filling period of wheat (Rosenzweig and Tubiello 1996), with an average yield reduction of $6 \%$ for each degree $\left({ }^{\circ} \mathrm{C}\right)$ of temperature increase (Asseng et al. 2015). Maize yields are reduced at daily maximum temperatures $>29{ }^{\circ} \mathrm{C}$ (Schlenker and Roberts 2009). Above $32{ }^{\circ} \mathrm{C}$, cotton yields fall due to a decline in leaf area, shoot biomass, and flowering (Schlenker and Roberts 2009). Alfalfa can be productive in warm climates when irrigated, yet temperatures $>30^{\circ} \mathrm{C}$ result in earlier flowering and reduced yield, poorer quality, and diminished suitability for lactating dairy animals (Al-

2 Earth and Environmental Science Area, Lawrence Berkeley Laboratories, Berkeley, CA, USA

3 Department of Environmental Science, Policy, and Management, University of California Berkeley, Berkeley, CA, USA

4 University of Idaho, Moscow, ID, USA

5 University of California at Davis, Davis, CA, USA

6 Natural Resource Conservation Service, Washington, DC, USA

7 New Mexico State University, Las Cruces, Mexico

8 Crops Pathology and Genetics Research Service, USDA-Agricultural Research Service, Davis, CA, USA 
Hamdani 1990; Greenfield and Smith 1973; Vough and Marten 1971). For crops in areas that are near such optimal temperature thresholds, such as maize and cotton in parts of the SW (Schlenker and Roberts 2009), additional warming could further reduce yield, which could impact food prices and security (Lobell et al. 2009). Beyond optimal temperatures, many crops fail as temperatures approach $35{ }^{\circ} \mathrm{C}$ (Table 1), though cotton can be grown at temperatures $>40{ }^{\circ} \mathrm{C}$. Complete crop failure is often due to reproductive failure during specific phenological phases (Baker et al. 1995; Lobell et al. 2007; Robertson et al. 2013).

This study examines the potential detrimental impacts of projected temperature shifts on eight FC that are cultivated widely in the SW, including small grains (wheat, barley, and oats), alfalfa, maize, cotton, rice, and safflower. These crops were grown on 5.2-M acres at a production value of $\$ 6.9 \mathrm{~B}$ in the $\mathrm{SW}$ in 2012 . The yield per area of most FC has increased in the SW since the 1880s, while the acreage of the barley, oats, wheat, and cotton has decreased in more recent times (1980 to present) (Online Resource (OR) 1). These crops vary in their spatial extents and growing temperature ranges; for example, hay is cultivated ubiquitously across the region, but other crops such as rice, cotton, and safflower are more geographically constrained. Much of the SW FC production provides food for livestock. In 2012, hay represented 35\% of the total regional FC acres harvested. Maize occupied $10 \%$ of the total FC acres harvested. Wheat, cotton, and rice each comprised 6-9\% of the 2012 total. Some analyses presented here focus on select crops. For example, the thermal range analyses include only alfalfa, maize, and cotton because of the higher spatial data accuracy, large cultivated acreage (alfalfa and cotton), and historic importance to indigenous people (maize) (Lynn et al. 2013). Maize and cotton were selected for yield analyses because of their differing temperature thresholds (Walthall et al. 2012) and cultivation in many parts of the region (National Agricultural Statistics Service 2013). We specifically seek to understand which FC and geographic regions of the SW may be most sensitive to projected changes in temperature.

\section{Methods}

Four analyses at varying spatial scales were conducted to assess impacts of temperature change by midcentury (2040-2069) on eight common FC grown across the SW USA.

\subsection{County-level impact assessment}

A county-level assessment was performed using county-by-county harvested FC area from the most recent US agricultural census (NASS 2013; Fig. 1), projected estimates of increased temperature and a crop sensitivity factor (SF) to estimate impact. The assessment of climate impacts on regional FC was based upon the framework defining vulnerability as a function of exposure, sensitivity, and adaptive capacity (Glick et al. 2011). The exposure of crops (wheat, barley, oats, alfalfa, maize, safflower, rice, and cotton) in each county to rising temperatures was represented by the projected future midcentury temperature for each county from the county-level summer (June-July-August) future maximum temperature $\left(T_{\max }\right)$ compiled from Multivariate Adaptive Constructed Analogs (MACA, Abatzoglou and Brown 2012) 20-model mean downscaled data for the 2040-2069 time period from the Representative Concentration Pathway 8.5 (RCP8.5) experiment (Elias et al. 2017).

The sensitivity of FC to changing temperatures was estimated using a literature-derived SF on a scale of 1 to 3 to represent general thermal sensitivities where crops classified as 1 are the 


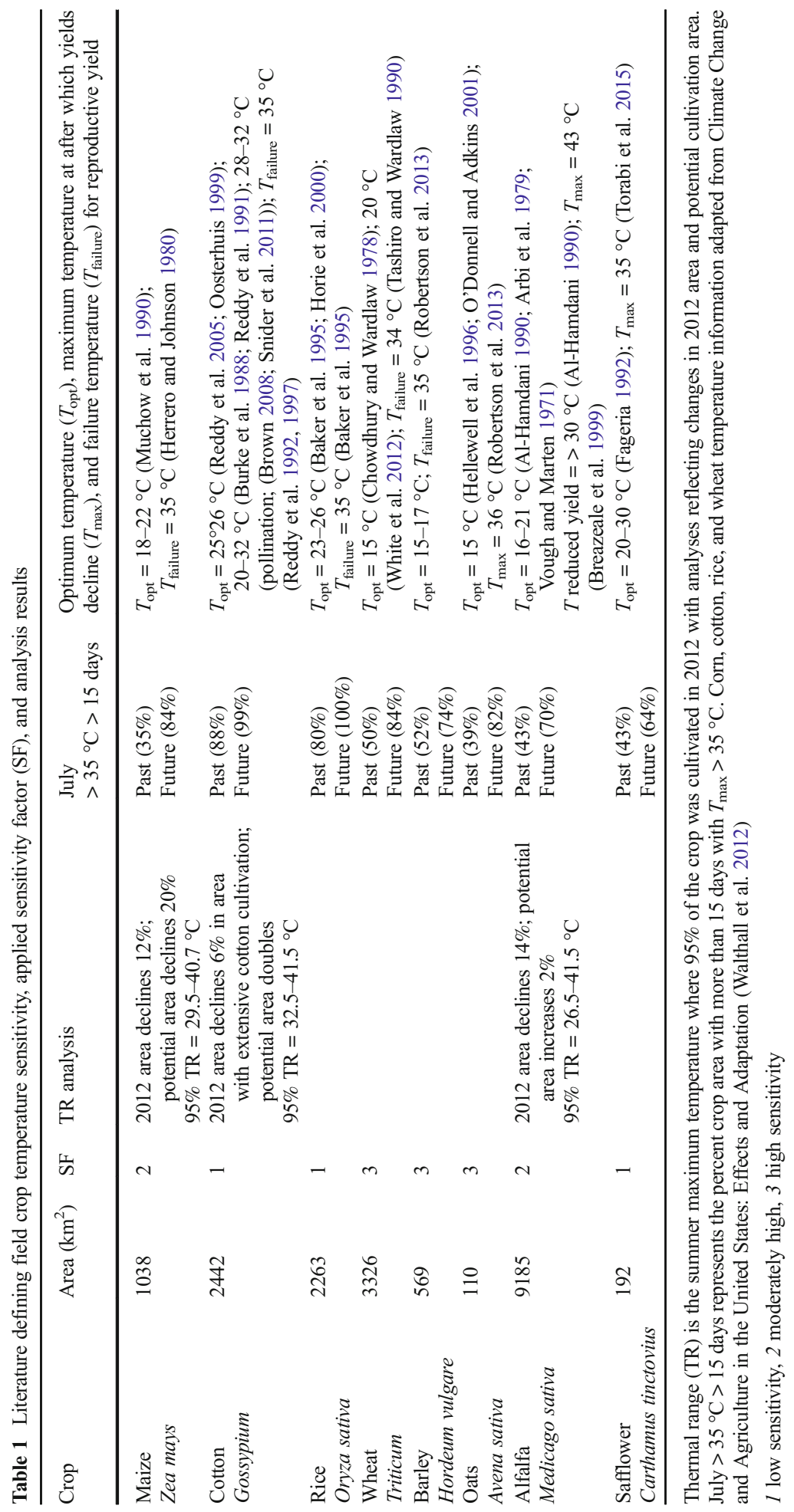




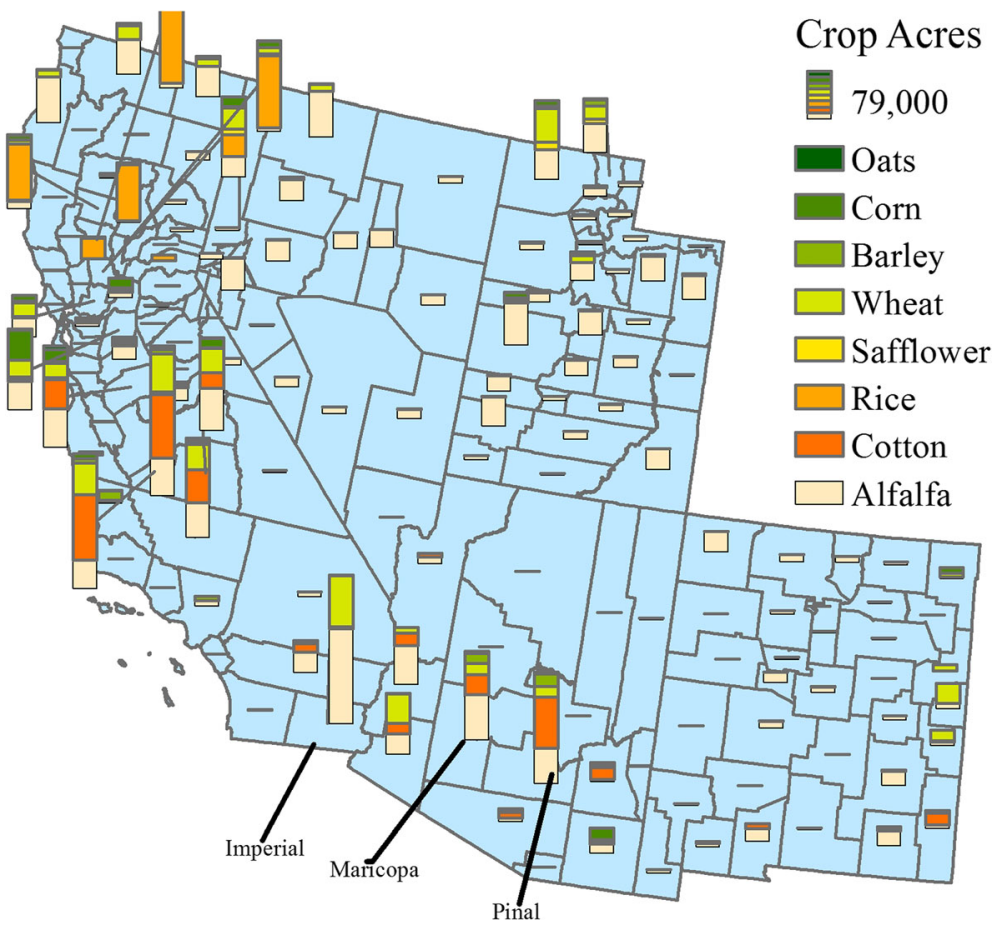

Fig. 1 County-based location of eight common field crops grown in the Southwestern USA in 2012

least sensitive to heat stress (cotton, rice, and safflower) and crops classified as 3 are the most sensitive to heat stress (small grains). Counties were indexed by $i$ where $i=\{1, \ldots, 152\}$. Crops are indexed by $j$ where $j=\{1, \ldots, 8\}$. To calculate the absolute sensitivity (sensitivity ${ }_{\mathrm{ABS}}$ ) of an individual crop within a county, we multiplied the area of a specific crop in a county $\left(A_{\text {crop }}\right)$ by the crops' SF value. We then summed the crop sensitivities for each FC for each county (Eq. 1). Relative sensitivity was calculated by dividing sensitivity ${ }_{\mathrm{ABS}}$ by the total $\mathrm{FC}$ acreage of the eight crops evaluated per county (Eq. 2).

$$
\begin{gathered}
\text { Sensitivity }_{A B S(i)}=\sum_{j=1}^{8}\left(\text { Acrop }_{i j}\right)\left(S F_{j}\right) \\
\text { Sensitivity }_{R E L(i)}=\frac{\text { SensitivityABS }}{\text { county field crop } \text { area }_{i}}
\end{gathered}
$$

Absolute impact ( Impact $_{\mathrm{ABS}}$ ) of changing temperatures was calculated for each county by multiplying crop area, sensitivity, and $T_{\max }$ (Eq. 3). The county products for each crop were summed, weighting counties with more FC more heavily.

$$
\begin{gathered}
\text { Impact }_{A B S(i)}=\sum_{j=1}^{8}\left(\text { Acrop }_{i j}\right)\left(S F_{j}\right)\left(\text { Tmax }_{i}\right) \\
\text { Impact }_{R E L(i)}=\frac{\text { ImpactABS }_{(\mathrm{i})}}{\text { county field crop } \text { area }_{\mathrm{i}}}
\end{gathered}
$$


The impact ${ }_{\mathrm{ABS}}$ was divided by the total area of FC (up to eight) analyzed in the county to calculate relative impact (Eq. 4).

Absolute values depict counties with a larger FC area and higher SF as more vulnerable to increased midcentury temperatures, whereas relative values show counties with a higher proportion of sensitive crops as more vulnerable to increased temperatures. The metrics are complementary and describe FC vulnerability from both an area and composition perspective.

\subsection{Shifting thermal range for alfalfa, maize, and cotton}

The geographic distribution of suitable land for cultivating three FC (alfalfa, cotton, and maize) was modeled based on thermal ranges (TR) for historic and future climate. The fundamental assumption of this component of the spatial FC assessment was that crops are presently grown in locations well-suited to their thermal tolerance. The FC for this analysis were selected due to regional importance and crop classification accuracy or how well the USDA cropland data layer (CDL) represents field-verified data (OR2). The CDL is cropspecific land cover data created annually for the contiguous USA using satellite imagery and extensive physical verification (i.e., ground-truthing).

The normal TR for each crop was generated using 2012 crop distribution of USDA CDL and summer (June-August) 30-year mean temperature normal (1971-2000) from PRISM (Daly et al. 2008). The TR was defined by the 95\% range (2.5-97.5 percentile) of climatological summer temperature coincident with the location of each crop of the CDL.

The future summer $T_{\max }$ was based on the MACA 20-model midcentury (2040-2069) multi-model mean temperature (RCP8.5) (Abatzoglou and Brown 2012). This dataset used PRISM and hence there are nominal differences between 30-year normals from historical climate experiments and observations from 1971 to 2000, hence allowing us to directly use and compare temperature projections from downscaled data with the TR developed from historical PRISM data. Public lands, urban areas, and water bodies were removed from analyses as they are unlikely to transition to agricultural land. Temperature rules were defined based upon the minimum and maximum temperatures bounding the normal 95\% TR for alfalfa, maize, and cotton to produce change detection maps showing areas predicted to shift into or outside the TR.

\subsection{Days with temperatures $>35^{\circ} \mathrm{C}$}

Since temperatures $>35{ }^{\circ} \mathrm{C}$ can be associated with reproductive failure, we analyzed the number of historic and future days by percent crop area where daily maximum temperature $>35{ }^{\circ} \mathrm{C}$ for April-August. Daily maximum temperature for both historic (1950-2005) and RCP8.5 experiments using the mean of the 20 models of MACA were obtained for each $~ 4-$ $\mathrm{km}$ pixel where crops were grown in 2012 per the CDL.

\subsection{Effects of temperature on yield}

Effects of historic (1950-2005) and midcentury (2040-2069) temperature on maize and cotton yields were estimated based on non-linear relationships between yields and hourly temperature exposures (Schlenker and Roberts 2009). Schlenker and Roberts found statistical relationships between yield declines and the number of hours at each degree interval for corn and cotton during the growing season (OR3). Accordingly, we constructed hourly 
temperature estimates by temporally disaggregating daily summer $T_{\max }$ and $T_{\min }$ for AprilAugust for all 20 models included in MACA historical and midcentury time periods, using a modified sinusoidal curve function (Linvill 1990). The cumulative number of hours of crop exposure to each $1{ }^{\circ} \mathrm{C}$ increment from 32 to $34{ }^{\circ} \mathrm{C}$ and $>=35{ }^{\circ} \mathrm{C}$ were calculated for each pixel and time period. Measures of heat exposure were multiplied by the yield reduction factors of Schlenker and Roberts (2009). Since yield reduction factors are timeseparable and additive, they were summed to estimate the total effect of heat stress on historical and midcentury maize and cotton yields. Cotton and maize exposure were based upon the 2012 location and density from the CDL. Each pixel was weighted by the fraction of area cultivated by each crop to calculate the average yield reduction factors for maize and cotton (NASS 2016).

\section{Results}

\subsection{County-level assessment}

County-level analyses of midcentury climate impacts on FC depict regions expected to be particularly vulnerable (Fig. 2). Absolute sensitivity and impact highlights the southern portion of California's Central Valley and counties along the California-Arizona border with higher sensitivity and impact to FC than other parts of the SW. Two areas of particular relative vulnerability are California's Central Coast and eastern New Mexico, as they both cultivate a high percentage of small grains. Only Imperial County, California is in both the highest absolute and relative impact classifications, indicating it may be especially vulnerable.

\subsubsection{Sensitivity}

Imperial County, California sensitivity ${ }_{\mathrm{ABS}}$ was highest in the region because it contained both the largest FC area and a large percentage of crops with a high SF value (35\%) (OR4). The

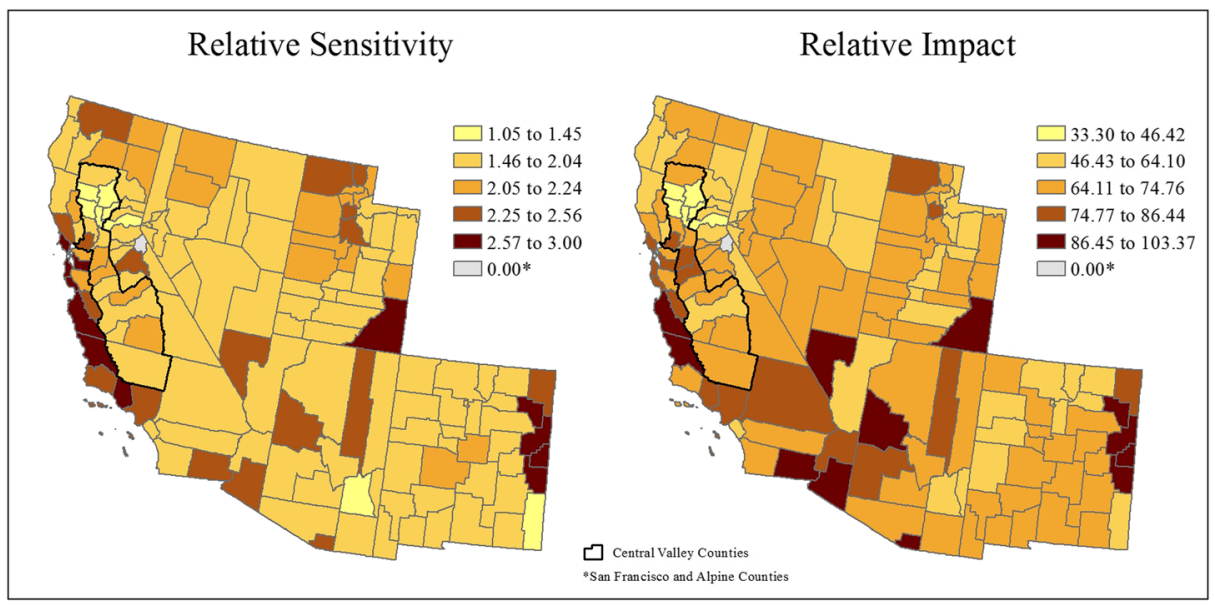

Fig. 2 Relative sensitivity and impact of field crops common to the Southwestern USA. For absolute sensitivity, 1 represents the least sensitive category 
southern Central Valley was a sensitive region based upon sensitivity ${ }_{\mathrm{ABS}}$, reflecting the large FC acreage dominated by alfalfa and wheat production. In contrast, north Central Valley counties have a large $\mathrm{FC}$ acreage, but lower sensitivity ${ }_{\mathrm{ABS}}$ because rice, classified with a lower $\mathrm{SF}$, comprises a large proportion of the total FC area. Other counties with high sensitivity ${ }_{\mathrm{ABS}}$ had a high total FC area.

Sensitivity $_{\text {REL }}$ enables the intercomparison of counties within the region according to

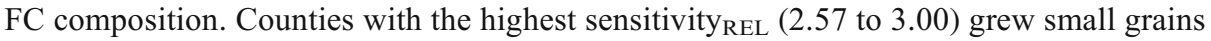
as more than half the total FC area (57-100\%). Eastern New Mexico had high sensitivity ${ }_{\text {REL }}$ because of cultivation of small grain crops, comprising at least $73 \%$ of the total FC production. The southern Central Valley appears moderately sensitive based on sensitivity $_{\text {REL }}$ but highly sensitive using absolute values. Similar to sensitivity ${ }_{A B S}$, the north Central Valley is a region of lower sensitivity due to the larger fractional area devoted to rice cultivation. The two counties with cotton comprising the largest proportion of total FC growth (Kings and Fresno, California) were classified with the highest sensitivity ABS but low sensitivity ${ }_{\text {REL }}$.

\subsubsection{Exposure}

Exposure is incorporated into impact $_{\mathrm{ABS}}$ and impact $_{\mathrm{REL}}$ analyses as the midcentury summer $T_{\max }$ by county (OR5). Future values range from 23 to $43{ }^{\circ} \mathrm{C}$, approximately $2.4-4.0{ }^{\circ} \mathrm{C}$ warmer than historical values, with the warmest temperatures in counties of the Sonoran Desert.

\subsubsection{Impact}

The four counties with large rice cultivation area (76-95\%) had lower impact ${ }_{\mathrm{ABS}}$ than other counties with similar area under cultivation but composed of different crops (OR6). Conversely, Yuma, Arizona, had a higher impact ABS $_{\text {than }}$ other counties with similar crop area due to cultivation of nearly $50 \%$ sensitive crops (48\% wheat) near the upper bounds of optimal temperatures $\left(T_{\max } \sim 40{ }^{\circ} \mathrm{C}\right.$ ). Future $T_{\max }$ is projected to be $43.2{ }^{\circ} \mathrm{C}$. Imperial, Fresno, and

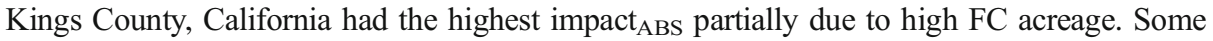

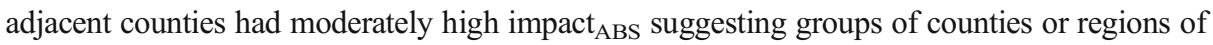
higher vulnerability.

Normalized to county area, impact ${ }_{\text {REL }}$ emphasizes the role of crop composition within a county to assess impacts of increasing temperatures on FC. Counties with a higher proportion of resilient crops were less affected by increased temperatures. The

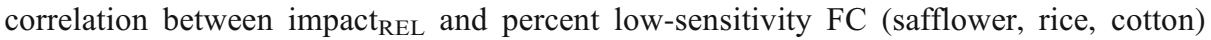
grown in each county exhibited a negative correlation $(r=-0.21 ; p=0.01)$. By

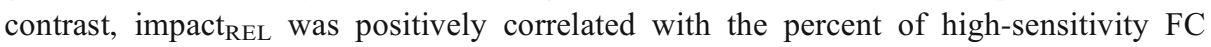
(wheat, barley, oats) grown in each county $(r=0.28 ; p=0.0004)$. While the Central Valley appeared less impacted based on impact $_{\mathrm{REL}}$ than impact $_{\mathrm{ABS}}$, counties of eastern New Mexico growing wheat appeared more impacted, with Quay County (90\% wheat) having the highest impact $_{\text {REL }}$. The Central Valley had counties with high impact $_{\mathrm{ABS}}$ primarily because of the large FC cultivation in that region whereas eastern New Mexico had a high impact ${ }_{\text {REL }}$ because of cultivation of sensitive crops. Only Imperial, California was in the most affected category using both impact $_{\mathrm{ABS}}$ and impact $_{\mathrm{REL}}$ (OR6). 


\subsection{Thermal range}

Projected increases in midcentury temperatures cause the area that is thermally suitable for cotton production to double by midcentury, with a northward expansion of potential area for cotton cultivation (OR7). However, $6 \%\left(158 \mathrm{~km}^{2}\right)$ of the 2012 cotton cultivation area, located in parts of California, Arizona, and Nevada, is projected to shift outside cotton's TR (32.5$41.5^{\circ} \mathrm{C}$ ) by midcentury, for a net gain in suitable area of $207,000 \mathrm{~km}^{2}$ in the SW.

The alfalfa cultivation area (2012) within the $95 \%$ summer $T_{\max }$ normals $\left(26.5-41.5{ }^{\circ} \mathrm{C}\right)$ will decrease by $14 \%\left(1508 \mathrm{~km}^{2}\right)$ by midcentury. Regions impacted by future temperatures are California's Imperial Valley, the lower Colorado River Valley along the California-Arizona border, and the Gila River corridor west of Phoenix. Across the SW, the area where alfalfa could be grown and remain within its TR (i.e., potential area) will increase by $2 \%$ by midcentury, for a net gain of $11,600 \mathrm{~km}^{2}$.

Twelve percent $\left(300 \mathrm{~km}^{2}\right)$ of maize cultivation area (2012) $\left(2504 \mathrm{~km}^{2}\right)$ will shift outside the TR $\left(29.5-40.7^{\circ} \mathrm{C}\right)$ by midcentury. The potential area within maize's TR in the SW is projected to decrease by $20 \%$ for a net loss of $88,900 \mathrm{~km}^{2}$. Regions of northern New Mexico along the Rio Grande Valley will shift into maize's normal TR, whereas portions of southern Arizona will have temperatures above maize's TR (OR7).

\subsection{Crop exposure to elevated temperature}

The projected number of days with maximum temperatures $>35^{\circ} \mathrm{C}$ will increase by midcentury across the region, varying by both month and crop (OR8 and OR 9). For all crops, July had the most days $>35{ }^{\circ} \mathrm{C}$ across the greatest spatial extent. Based on 2012 crop locations, the crops exposed to more than 15 days $>35^{\circ} \mathrm{C}$ in July ranged from a low of $35 \%$ (maize) to a high of $88 \%$ (cotton). By midcentury, this range increases to $64 \%$ (safflower) to $100 \%$ (cotton and rice). The increase in area $>15$ days $>35^{\circ} \mathrm{C}$ was highest for oat and maize, indicating that they may experience the broadest change in area impacted by midcentury July heat stress.

\subsection{Effects of temperature on yield}

Historically (1950-2005), between April and August, corn received an average of $426 \mathrm{~h}$ $>32{ }^{\circ} \mathrm{C}$. Average temperatures at historic (1950-2005) cotton cultivation locations $(2012$ $\mathrm{CDL}$ ) were higher than corn cultivation locations, with average exposure of $622 \mathrm{~h}>32{ }^{\circ} \mathrm{C}$ for cotton. Using our temperature-yield effects model (Eq. 1; OR3), heat stress reduced historical yields (1950-2005) by $18 \%$ for maize and $26 \%$ for cotton (OR3). Average historical yields (1950-2005) were 7,774 kg/ha for maize and $1140 \mathrm{~kg} / \mathrm{ha}$ for cotton, so yield potentials without heat stress would have been 9420 and $1540 \mathrm{~kg} / \mathrm{ha}$ for maize and cotton, respectively. By midcentury (2040-2069), corn will have an average exposure of $665 \mathrm{~h}>32{ }^{\circ} \mathrm{C}\left(88 \mathrm{~h}\right.$ at $32{ }^{\circ} \mathrm{C}, 85 \mathrm{~h}$ at $33{ }^{\circ} \mathrm{C}, 81 \mathrm{~h}$ at $34{ }^{\circ} \mathrm{C}$, and $411 \mathrm{~h}$ at $35^{\circ} \mathrm{C}$ or greater $)$. Cotton exposure was $918 \mathrm{~h}>32{ }^{\circ} \mathrm{C}\left(101 \mathrm{~h}\right.$ at $32{ }^{\circ} \mathrm{C}, 96 \mathrm{~h}$ at $33{ }^{\circ} \mathrm{C}, 89 \mathrm{~h}$ at $34{ }^{\circ} \mathrm{C}$, and $632 \mathrm{~h}$ at $35{ }^{\circ} \mathrm{C}$ or greater) by midcentury. Consequently, heat stress would reduce yields by $27 \%$ for maize and $38 \%$ for cotton. Assuming all factors other than temperature are consistent, midcentury yields will be reduced by 12 and $15 \%$ of historic yields for maize and cotton, which would be 6860 and $964 \mathrm{~kg} / \mathrm{ha}$ for corn and cotton, respectively. The southern Central Valley, eastern New Mexico, and southern Arizona would suffer the greatest impacts by midcentury. 


\section{Discussion}

\subsection{Temperature impacts on specific crops}

Small grains The relatively high sensitivity of small grains to elevated temperatures led to increases in county impact ${ }_{\text {REL }}$ in counties with a higher proportion therein. In the future, a larger portion of the area currently occupied by barley, oat, and wheat across the SW will have more days $>35^{\circ} \mathrm{C}$. Already, early planting of small grains, or sowing in fall and harvesting in late spring or early summer, serves as a heat stress adaptation strategy.

Alfalfa Alfalfa is cultivated in nearly all SW counties, but Imperial County, California, grows the largest acreage. The projected shift outside the $95 \%$ TR by midcentury for nearly all the alfalfa cultivation area in Imperial County underscores the need to use strains with broad adaptation to elevated temperature to support both yield and quality (Arbi et al. 1979). Portions of northern California and Arizona will provide a thermal regime similar to the historic TR and may be better suited to growing future high-quality, high-yield alfalfa. Our results showed $70 \%$ of the SW alfalfa cultivation area with $>15$ days $>35^{\circ} \mathrm{C}$ in July by midcentury. This increase may cause decreased evaporative cooling, increased heat stress, and summer slump in yield and quality (Putnam and Ottman 2013).

Maize TR analyses showed that maize grown in southern AZ will be outside historic summer temperatures by midcentury. Most maize in the SW is grown in the Central Valley (CA), where mean summer $T_{\max }$ is projected to remain within the normal TR (OR7). However, monthly analysis reveals that the area encompassing the Central Valley is projected to be $>35^{\circ} \mathrm{C}$ for $>20$ days in July and August and may hinder future production. Yield analyses estimate that heat stress will reduce potential maize yield across the SW by $27 \%$ by mid-century, an additional $12 \%$ decline over historic impacts of heat stress on yields (OR3). Others have reported sensitivity of maize to projected climate changes in the region (Hatfield et al. 2011).

Cotton Counties with high cotton cultivation generally had a moderate to high sensitivity ${ }_{\mathrm{ABS}}$ and impact $_{\mathrm{ABS}}$ because they also had a large total FC area. The lower sensitivity ${ }_{\mathrm{REL}}$ and impact $_{\mathrm{REL}}$ reflect its SF value. Still, the cotton TR is projected to double by midcentury due to its northward expansion. The CA cotton region will remain within the normal TR, with some northern areas transitioning into the normal TR. Other parts of the SW may pose a challenge for future cotton cultivation despite low sensitivity and broader TR. Specifically, areas projected to transition from the historic TR are located in counties presently with large cotton cultivation (Pinal and Maricopa, Arizona).

Since cotton is normally planted in April in Arizona and California and generally takes 2 months from planting to first flower, June temperatures are important indicators of crop failure due to heat stress during reproduction. In the past, $30 \%$ of the cotton area had $>15$ days $>35{ }^{\circ} \mathrm{C}$ in June. By midcentury, this number increases to $80 \%$, potentially leading to diminished yields due to impacts on floral development and boll abortion 15 days postflowering (Brown 2008). Cotton cultivation area with an average of more than 26 days $>35{ }^{\circ} \mathrm{C}$ in July is projected to increase from 20 to $66 \%$ by midcentury. Heat stress was projected to reduce yields by $15.4 \%$ compared to historic yields and $38 \%$ compared to potential yields if future production remains in the same location as the 2012 CDL. However, 
the northward expansion of cotton's TR indicates that production could relocate to a more suitable TR and thereby maintain acceptable yields, given suitable soils and available water.

Rice Rice is cultivated only in seven counties in northern CA where early planting in April or May increases yields (Linquist and Espe 2016). Planting early maximizes the use of solar radiation. It also diminishes potential exposure to temperatures $>35{ }^{\circ} \mathrm{C}$ at flowering, which increases rice sterility (Satake 1995). Early planting will become increasingly important by midcentury, since July and August are projected to have 5 to 10 days with $T_{\max }>35^{\circ} \mathrm{C}$ (OR9).

Safflower Safflower prefers hot, arid conditions and accordingly nearly half of the nation's safflower is grown in the SW. Even though current acreage represents the crop with the smallest percentage $>15$ days $>35^{\circ} \mathrm{C}$ in July, its midcentury cultivation area with $>15$ days $>35{ }^{\circ} \mathrm{C}$ increases by $21 \%$. Most safflower is not irrigated so the cumulative effects of increased temperature on water and heat stress could impact production.

\subsection{Yield effects}

The timing of extreme heat events has important repercussions on plant physiology. Heat increases the rate of crop development, which consequently decreases growing time (Lobell et al. 2007). This can simply reduce yields or can result in physiological defects. Yield reduction may occur because plants close their stomata at temperatures above the temperature optimum. The effect of temperature on photosynthesis depends on the current temperature compared to the optimum (Rosenthal et al. 2012); maximum summer temperatures are already near the upper optimal limits for maize and cotton (Schlenker and Roberts 2009), so increased heat will likely decrease photosynthesis for both crops. During reproduction, heat stress may reduce the effectiveness of pollinators, reduce grain set, and even cause sterility (Lobell et al. 2007).

\subsection{Reducing temperature risk}

The identification of thermal vulnerabilities guides adaptive responses to reduce temperature risk. Growers can mitigate crop heat stress by increasing irrigation (Haim et al. 2008), which provides evaporative cooling, allowing crops to persist in locations hotter than reported thermal ranges. Crop production is supported by the SW's extensive surface water infrastructure managed by various agencies. These systems transport water over large distances, geographically decoupling water sources, such as high-mountain snowpack, from water users. Without access to surface water conveyance networks, growers consequently rely upon groundwater. Some counties, including those in eastern NM, do so to support all agricultural production. While groundwater's strategic importance for global food security increases (Taylor et al. 2013), groundwater tables are declining in parts of the region (Konikow 2013). Delivering adequate water to mitigate heat stress and maintain yields may be a challenging or even impossible adaptation strategy with predicted changes in precipitation (Langford et al. 2014), reductions in water supply (Schoups et al. 2005), and increases in water scarcity (Averyt et al. 2013).

Another adaptation option for elevated temperatures may be earlier planting to adjust for temperature shifts. Different field crops are typically sown and harvested at different times throughout the year (OR10) (National Agricultural Statistics Service 2010). The crops considered here were cultivated during part or all of the summer (June-July-August). Some crops, 
such as oat and barley in California, have two different planting cycles with both spring and fall planting phases. Others have very different growth periods due to geography. Planting and sowing dates for winter wheat, for example, cover only 4 months in colder states (NV and UT) as compared with 9 months in Arizona. Thus, warming may extend growing seasons in parts of the region. However, using Arizona growers as an example, which generally practice single season planting and harvesting, extended warming may not elicit cultivation of multiple yields within 1 year. Sowing date and time of flowering and maturity in cereal phenology by 2040 may advance by 1-3 weeks in Northern and Central Europe under a changed climate (Olesen et al. 2012). However, earlier spring onset can increase vegetation frost damage risk (Kim et al. 2014) or lead to decreased yield from reduced day length. Simply shifting planting dates to accommodate warming trends may not be a consistently viable adaptation. Growers may select drought tolerant cultivars or, where possible, practice deficit irrigation to ensure enough available water during critical periods like flowering. The effects of diminished water supply increased heat stress and crop yield reduction compound vulnerabilities for regional crop production.

These spatially explicit findings on temperature enable prioritization of regions for examination of adaptation scenarios, especially if overlaid with existing and projected water resources. These scenarios should include biophysical, agricultural, and socioeconomic factors among the current suite of indicators assessed here to build resilient production systems (Steenwerth et al. 2014). Climate change impacts (for example, higher temperatures and $\mathrm{CO}_{2}$ concentrations, increased drought and flooding) may be somewhat ameliorated by advances in crop physiology and genetics. However, there are social controversies surrounding genetic engineering. Since adaptations often come at a physiological cost, the trade-offs in introducing new plant traits must be considered (Steenwerth et al. 2014). In addition, development of transgenic crops has been slow (Mittler and Blumwald 2010). Identification of representative target environments under future temperature regimes informs establishment of regional crop networks, where germplasm with increased heat and drought tolerance and agricultural practices that mitigate elevated temperatures can be developed.

\subsection{Beyond temperature}

Other factors besides increasing temperature will affect crop production. Changes to components of the hydrologic cycle, trending towards more arid conditions (Jones and Gutzler 2016), will ultimately reduce total water availability. Social and economic factors such as competition for dwindling water resources between varied sectors could reduce water supplied to crop production. Increasing $\mathrm{CO}_{2}$ concentrations can provide benefits for some plants, but projected changes in temperature and precipitation may outweigh any benefits associated with $\mathrm{CO}_{2}$ (Walthall et al. 2012). Also, impacts of such changes on pollination, weeds, pathogens, and pests will undoubtedly influence crop production.

\subsection{Conclusions}

County-level analyses of midcentury climate impacts (absolute and relative) on FC indicate particular vulnerability to increasing temperatures within California's southern Central Valley and the southern California/Arizona border. Imperial County's (CA) high vulnerability is due to extensive cultivation of highly sensitive FC therein. Depending upon the coincidence of extreme heat events with certain plant growth phases, more temperature-related crop failure is 
likely. For historic and midcentury analyses, July had the most days $>35^{\circ} \mathrm{C}$ across the greatest spatial extent. By midcentury, nearly all cotton and rice areas will have $>15$ days $>35{ }^{\circ} \mathrm{C}$ in July. Maize (12\%) and alfalfa (14\%) areas will shift outside normal summer maximum TR, while TR for cotton nearly doubles by midcentury. FC production is already limited by temperature impacts on yield potential in the SW USA. The historic range for maize and cotton already suffers yield reductions of 18 and $26 \%$, respectively, as compared with yield potential. We expect further reduced yields by midcentury compared to historic yields, such as a $15.4 \%$ yield reduction in cotton in its current locations. Relatively lower yield reductions in maize are anticipated as it covers a greater spatial extent and thus broader temperature conditions. Decision-making to adapt to climate change must integrate vulnerability of total regional crop acreage and its composition to future temperatures. This work demonstrates that viable locations where these FC might be established under future TR are presently occupied by high value specialty crops and other land uses, suggesting that the SW region will continue to grapple with the tensions among agriculture, conservation, and other land management goals and reflecting the situations encountered in many global regions as resources become impacted in our changing climate.

Acknowledgements This work is a contribution of the United States Department of Agriculture (USDA) Southwest Climate Hub. Manuscript development was supported by the USDA, Agricultural Research Service, Jornada Experimental Range with funding by the USDA (CRIS Project no. 3050-11210-007D) and the National Science Foundation (Grant DEB-0618210). We thank Connie Maxwell, Dustin Ward, Ryann Smith, Nathan Lopez-Brody, and Darren James.

Open Access This article is distributed under the terms of the Creative Commons Attribution 4.0 International License (http://creativecommons.org/licenses/by/4.0/), which permits unrestricted use, distribution, and reproduction in any medium, provided you give appropriate credit to the original author(s) and the source, provide a link to the Creative Commons license, and indicate if changes were made.

\section{References}

Abatzoglou JT, Brown TJ (2012) A comparison of statistical downscaling methods suited for wildfire applications. Int J Climatol 32:772-780

Al-Hamdani S (1990) Effect of temperature regimes on photosynthesis, respiration, and growth in alfalfa. Proceedings of the Oklahoma academy of science 70:1-4

Arbi N, Smith D, Bingham ET (1979) Dry matter and morphological responses to temperatures of alfalfa strains with differing ploidy levels. Agron J 71(4):573-577

Asseng S et al (2015) Rising temperatures reduce global wheat production. Nat Clim Chang 5:143-147

Averyt K, Meldrum J, Caldwell P, Sun G, McNulty S, Huber-Lee A, Madden N (2013) Sectoral contributions to surface water stress in the coterminous United States. Environ Res Lett 8(2013)035046:1-9

Baker JT, Boote KJ, Allen LH (1995) Potential climate change effects on rice: carbon dioxide and temperature. In: Rosenzweig C (ed) Climate change and agriculture: analysis of potential international impacts. American Society of Agronomy, pp 31-47. https://doi.org/10.2134/asaspecpub59.c2

Breazeale D, Kettle R, Munk G (1999) Using growing degree days for alfalfa production. University of Nevada Cooperative Extension. Reno, NV. Report number 99-71. Accessed online: https://www.unce.unr. edu/publications/files/ag/other/fs9971.pdf [1/2/2016]

Brown PW (2008) Cotton heat stress. 10 pp

Burke JJ, Mahan JR, Hatfield JL (1988) Crop-specific thermal kinetic windows in relation to wheat and cotton biomass production. Agron J 80(4):553

Chowdhury SI, Wardlaw IF (1978) The effect of temperature on kernel development in cereals. Aust J Agric Res 29(2):205

Craufurd PQ, Wheeler TR (2009) Climate change and the flowering time of annual crops. J Exp Bot 60:2529-2539

Daly C et al (2008) Physiographically-sensitive mapping of temperature and precipitation across the conterminous United States. Int J Climatol 28:2031-2064 
Elias E, Schrader TS, Abatzoglou JT, Crimmins M, Weiss J, Rango A (2017) County-level climate change information to support decision-making on working lands within USDA climate hub regions. Clim Change. https://doi.org/10.1007/s10584-017-2040-y

Fageria NK (1992) Maximizing crop yields. Marcel Dekker, Inc., New York, 271pp

Gershunov A, and Coauthors (2013) Future climate: projected extremes. assessment of climate change in the Southwest United States: A report prepared for the national climate assessment. In: Garfin G, Jardine A, Merideth R, Black M, LeRoy S (eds) Island Press/Center for Resource Economics, pp 126-147

Glick P, Stein BA, Edelson NA (eds) (2011) Scanning the conservation horizon: A guide to climate change vulnerability assessment. National Wildlife Federation, Washington, D.C., p 168

Greenfield PL, Smith D (1973) Influence of temperature change at bud on composition of Alfalfa at First Flower. Agron J 65(6):871-874

Haim D, Shechter M, Berliner P (2008) Assessing the impact of climate change on representative field crops in Israeli agriculture: a case study of wheat and cotton. Clim Chang 86:425-440

Hatfield J et al (2011) Climate impacts on agriculture: implications for crop production. Agron J 103:351-370

Hellewell KB, Stuthman DD, Markhart AH, Erwin JE (1996) Day and night temperature effects during grainfilling in oat. Crop Sci 36(3):624

Herrero MP, Johnson RR (1980) High temperature stress and pollen viability of Maize1. Crop Sci 20(6):796

Horie T, Baker JT, Nakagawa H, Matsui T, Kim HY (2000) Crop ecosystem responses to climatic change: rice. Climate change and global crop productivity, K. R. Reddy, and H. F. Hodges, Eds., CABI, 81-107

Jones SM, Gutzler DS (2016) Spatial and seasonal variations in aridification across Southwest North America. J Clim 29:4637-4649

Kim Y, Kimball JS, Didan K, Henebry GM (2014) Response of vegetation growth and productivity to spring climate indicators in the conterminous United States derived from satellite remote sensing data fusion. Agric For Meteorol 194:132-143

Konikow LF (2013) Groundwater depletion in the United States (1900-2008) scientific investigations report 2013-5079. U.S. Geological Survey, Reston, p 63

Langford S, Stevenson S, Noone D (2014) Analysis of low-frequency precipitation variability in CMIP5 historical simulations for southwestern North America. J Clim 27:2735-2756

Linquist B, Espe M (2016) When is the optimal time to plant rice in the Sacramento Valley? Available online at http://rice.ucanr.edu/files/232444.pdf

Linvill DE (1990) Calculating chilling hours and chill units from daily maximum and minimum temperature observations. HortSci 25:14-16

Lobell DB, Gourdji SM (2012) The influence of climate change on global crop productivity. Plant Physiol 160: 1686-1697

Lobell DB, Cahill KN, Field CB (2007) Historical effects of temperature and precipitation on California crop yields. Clim Chang 81:187-203

Lobell DB, Cassman KG, Field CB (2009) Crop yield gaps: their importance, magnitudes, and causes. Annu Rev Environ Resour 34:179-204

Lynn K et al (2013) The impacts of climate change on tribal traditional foods. Clim Chang 120:545-556

Marshall E, Aillery M, Malcolm S, Williams R (2015) Climate change, water scarcity, and adaptation in the U.S. Fieldcrop Sector, ERR-201. U.S. Department of Agriculture, Economic Research Service

Mittler R, Blumwald E (2010) Genetic engineering for modern agriculture: challenges and perspectives. Annu Rev Plant Biol 61:443-462

Muchow RC, Sinclair TR, Bennett JM (1990) Temperature and solar radiation effects on potential maize yield across locations. Agron J 82(2):338

National Agricultural Statistics Service Cropland Data Layer (2016) Published crop-specific data layer [Online]. Available at https://nassgeodata.gmu.edu/CropScape/. Accessed 1/2/2016. USDA-NASS, Washington, DC

National Agricultural Statistics Servics (2010) Field crops usual planting and harvesting dates. Agricultural Handbook Number 628. Accessed online: http://usda.mannlib.cornell.edu/usda/current/planting/planting-1029-2010.pdf. Accessed October 2010

National Agricultural Statistics Service (2013) 2012 Census of Agriculture. Accessed online: https://www.nass. usda.gov

O'Donnell CC, Adkins SW (2001) Wild oat and climate change: the effect of CO concentration, temperature, and water deficit on the growth and development of wild oat in monoculture. Weed Sci 49(5):694-702

Olesen JE et al (2012) Changes in time of sowing, flowering and maturity of cereals in Europe under climate change. Food Addit Contam Part A-Chem Anal Control Expos Risk Assess 29:1527-1542

Putnam DH, Ottman M (2013) Your alfalfa crop got the Blues? it may be 'Summer Slump'. Alfalfa and forage news: news and information from UC cooperative extension about alfalfa and forage production. University of Arizona Cooperative Extension 
Oosterhuis DM (1999) Yield response to environmental extremes in cotton. In: D.M. Oosterhuis (ed.). Proc. 1999 Cotton Research Meeting and Summaries of Research in Progress. University of Arkansas Agricultural Experiment Station Special Report 193:30-38

Reddy VR, Reddy KR, Baker DN (1991) Temperature effect on growth and development of cotton during the fruiting period. Agron J 83(1):211

Reddy KR, Hodges HF, Reddy VR (1992) Temperature effects on cotton fruit retention. Agron J 84(1):26

Reddy RK, Hodges HF, McKinion JM (1997) A comparison of scenarios for the effect of global climate change on cotton growth and yield. Aust J Plant Physiol 24(6):707

Reddy RK, Vara Prasad PV, Gopal Kakani V (2005) Crop responses to elevated carbon dioxide and interactions with temperature. J Crop Improv 13(1-2):157-191

Robertson SM, Jeffrey SR, Unterschultz JR, Boxall PC (2013) Estimating yield response to temperature and identifying critical temperatures for annual crops in the Canadian prairie region. Can J Plant Sci 93:12371247

Rosenthal DM et al (2012) Cassava about-FACE: greater than expected yield stimulation of cassava (Manihot esculenta) by future CO2 levels. Glob Chang Biol 18:2661-2675

Rosenzweig C, Tubiello FN (1996) Effects of changes in minimum and maximum temperature on wheat yields in the central USA simulation study. Agric For Meteorol 80:215-230

Satake T (1995) High temperature injury. Science of the rice plant. Volume 2: Physiology, Food and Agriculture Policy Research Center, pp 1240

Schlenker W, Roberts MJ (2009) Nonlinear temperature effects indicate severe damages to U.S. crop yields under climate change. Proc Natl Acad Sci 106:15594-15598

Schoups G, Hopmans JW, Young CA, Vrugt JA, Wallender WW, Tanji KK, Panday S (2005) Sustainability of irrigated agriculture in the San Joaquin Valley, California. Proc Natl Acad Sci U S A 102:15352-15356

Snider JL, Oosterhuis DM, Kawakami EM (2011) Diurnal pollen tube growth rate is slowed by high temperature in field-grown Gossypium Hirsutum pistils. J Plant Physiol 168(5):441-448

Steenwerth et al (2014) Climate-smart agriculture global research agenda: scientific basis for action. Agric Food Sec 2014 3:11. https://doi.org/10.1186/2048-7010-3-11

Tashiro T, Wardlaw IF (1990) The response to high temperature shock and humidity changes prior to and during the early stages of grain development in wheat. Aust J Plant Physiol 17(5):551

Taylor RG et al (2013) Ground water and climate change. Nat Clim Chang 3:322-329

Torabi B, Adibniya M, Rahimi A (2015) Seedling emergence response to temperature in safflower: measurements and modeling. Int J Plant Prod 9:393-411

Vough LR, Marten GC (1971) Influence of soil moisture and ambient temperature on yield and quality of alfalfa forage. Agron J 63:40-42

Walthall CL, and Coauthors (2012) Climate change and agriculture in the US: effects and adaptation. USDA Technical Bulletin \#1935, Washington, DC., pp 186

White JW, Kimball BA, Wall GW, Ottman MJ (2012) Cardinal temperatures for wheat leaf appearance as assessed from varied sowing dates and infrared warming. Field Crop Res 137:213-220 